\title{
Interaction with a Host Ubiquitin-Conjugating Enzyme Is Required for the Pathogenicity of a Geminiviral DNA $\beta$ Satellite
}

\author{
Omid Eini, ${ }^{1,2,3}$ Satish Dogra, ${ }^{1}$ Luke A. Selth, ${ }^{1}$ Ian B. Dry, ${ }^{2}$ John W. Randles, ${ }^{1}$ and M. Ali Rezaian ${ }^{1}$ \\ ${ }^{1}$ School of Agriculture, Food and Wine, The University of Adelaide, Waite Campus, SA 5064, Australia; ${ }^{2}$ CSIRO Plant Industry, \\ PO Box 350, Glen Osmond, SA 5064, Australia; ${ }^{3}$ Plant Protection Department, College of Agriculture, Zanjan University, \\ Zanjan, Iran
}

Submitted 4 November 2008. Accepted 29 January 2009.

DNA $\beta$ is a single-stranded satellite DNA which encodes a single gene, $\beta C 1$. To better understand the role of $\beta C 1$ in the pathogenicity of DNA $\beta$, a yeast two-hybrid screen of a tomato cDNA library was carried out using $\beta C 1$ from Cotton leaf curl Multan virus (CLCuMV) DNA $\beta$ as the bait. A ubiquitin-conjugating enzyme, designated $S I U B C 3$, which functionally complemented a yeast mutant deficient in ubiquitin-conjugating enzymes was identified. The authenticity and specificity of the interaction between $\beta C 1$ and SIUBC3 was confirmed both in vivo, using a bimolecular fluorescence complementation assay, and in vitro, using a protein-binding assay. Analysis of deletion mutants of the $\beta C 1$ protein showed that a myristoylation-like motif is required both for its interaction with SIUBC3 and the induction of DNA- $\beta$-specific symptoms in host plants. The level of polyubiquitinated proteins in transgenic tobacco plants expressing $\beta \mathrm{C} 1$ was found to be reduced compared with wild-type plants. These results are consistent with the hypothesis that interaction of $\beta C 1$ with $\mathrm{SIUBC3}$ is required for DNA- $\beta$-specific symptom induction, and that this is possibly due to downregulation of the host ubiquitin proteasome pathway.

Geminiviruses are a large and diverse family of plant-infecting pathogens segregated into four genera based on genome structure, insect vectors, and host range. The genus Begomovirus (type member, Bean golden yellow mosaic virus) is the largest grouping within the family Geminiviridae. Members of this genus have either monopartite or bipartite single-stranded DNA genomes. They are transmitted by whiteflies and only infect dicotyledonous plants (Stanley et al. 2005). Begomovirus spp. are considered one of the largest and most successful groups of plant viruses and are responsible for numerous diseases of economically important crops, such as cassava, cotton, bean, pepper, and tomato (Brown 1992; Moriones and NavasCastillo 2000; Polston et al. 1994).

Nucleotide sequence data of SIUBC3 is available in the GenBank database under accession number FJ429328.

Corresponding author: Omid Eini;

E-mail: omid.einigandomani@adelaide.edu.au

* The $\boldsymbol{e}$-Xtra logo stands for "electronic extra" and indicates four supplemental figures and one supplemental table are published online. In addition, Figures 4 and 8 appear in color online.
Geminiviral encoded proteins have been shown to be responsible for the production of abnormal phenotypes in infected plants through interactions with host factors which are involved in various metabolic pathways. For example, expression of the C4 gene from Beet curly top virus (BCTV) in Nicotiana benthamiana resulted in abnormal phenotypes and produced tumors (Latham et al. 1997), and BCTV C4 interacts with three protein kinases: two members of the shaggy-related proteinase family (AtSK $\xi$ and AtSK $\eta$ ) and a leucine-rich repeat receptorlike kinase (LRR-RLK) (Piroux et al. 2007). This suggests that the BCTV $\mathrm{C} 4$ protein interacts with components of the brassinosteroid signaling pathway.

DNA $\beta$ is a circular, single-stranded satellite DNA associated with certain monopartite Begomovirus spp. which causes economically important diseases such as cotton leaf curl disease. DNA $\beta$ enhances the replication level of the helper virus in certain host plants (Briddon et al. 2001) and permits the movement of a bipartite Begomovirus sp. by replacing the DNA-B particle (Saeed et al. 2007). DNA $\beta$ contains a single gene, $\beta C 1$, which encodes a pathogenicity protein important for symptom expression (Cui et al. 2004; Jose and Ramakrishnan 2003; Qian and Zhou 2005; Saeed et al. 2005; Saunders et al. 2004) and suppression of gene silencing (Cui et al. 2005; Gopal et al. 2007; Kon et al. 2007). However, the process by which $\beta \mathrm{C} 1$ produces specific symptoms in Geminivirusinfected host plants is unknown. To address this question, a tomato cDNA library was introduced into a yeast two-hybrid $(\mathrm{Y} 2 \mathrm{H})$ system and screened for proteins which interact with $\beta C 1$ encoded by the DNA $\beta$ associated with Cotton leaf curl Multan virus (CLCuMV). This study describes the interaction of $\beta \mathrm{C} 1$ with the host ubiquitin proteasome pathway through its binding to a tomato ubiquitin-conjugating (UBC) enzyme, designated SIUBC3. In addition, a myristoylation-like motif of $\beta C 1$ is shown to be required for both the interaction with SIUBC3 and the induction of DNA- $\beta$-specific symptoms in host plants.

\section{RESULTS}

Identification of a novel UBC

from tomato that interacts with $\beta \mathrm{C} 1$.

To identify host proteins that interact with the $\beta \mathrm{C} 1$ protein of the DNA $\beta$ associated with CLCuMV (ClCuMV- $\beta \mathrm{C} 1$ ), a Y2H screen of a tomato cDNA library fused to the B42 activation domain (AD)-encoding sequence (Zhou et al. 1995) was performed using $\beta C 1$ from CLCuMV DNA $\beta$ fused to the LexA DNA-binding domain (BD) as bait. In total, $2 \times 10^{6}$ transfor- 
mants were assayed for leucine prototrophic growth and green fluorescent protein (GFP) activity and five transformants were identified that activated both reporter genes. The details of these five $\beta C 1$ interactor sequences ( $\beta C 1-I S)$ together with the closest matching sequence on the GenBank database are summarized in Table 1.

Based on alignment with the plant UBC sequences, it was found that clone $\beta C 1$-IS1 lacked 31 amino acids at the N-terminus. Therefore, we amplified the missing 5' cDNA sequence of $\beta$ C1-IS1 (Table 1) from tomato (cv. Grosse Lisse) leaf total RNA using 5' rapid amplification of cDNA ends (RACE) to generate a full-length clone. The putative 148-amino-acid translation product of full-length $\beta \mathrm{C} 1$-IS1 was found to be identical to a tomato UBC (accession number P35135), whereas the cDNA sequences of these two genes were significantly different, showing only $90.1 \%$ identity (data not shown). Therefore, we designate the new $\beta C 1$-IS1 clone as SIUBC3 to distinguish it as the third member of the tomato UBC gene family published in GenBank.

The UBC is a component of the ubiquitin proteasome pathway which is important for cell cycle regulation, and some human viruses have been shown to manipulate this pathway for their infection cycle (Banks et al. 2003); therefore, $\beta C 1$-IS1 was selected for further analysis.

\section{Functional testing of SIUBC3.}

The Arabidopsis genome contains 37 putative UBC proteins grouped into 16 subgroups (Kraft et al. 2005). Clustal alignment analysis of SIUBC3 with all members of the AtUBC

Table 1. $\beta C 1$ interactor sequences from tomato together with the closest matching sequence on the GenBank database

\begin{tabular}{|c|c|c|}
\hline $\begin{array}{l}\beta \mathrm{C} 1 \\
\text { interactor }\end{array}$ & $\begin{array}{l}\text { Amino } \\
\text { acids }^{\mathbf{a}}\end{array}$ & Closest matching sequence from BlastX \\
\hline$\beta C 1-I S 1$ & 112 & Ubiquitin-conjugating enzyme (P35135) \\
\hline$\beta C 1-I S 2$ & 307 & Urate oxidases (DQ365932) \\
\hline$\beta C 1-I S 3$ & 130 & Unknown protein (AK224698) \\
\hline$\beta C 1-I S 4$ & 278 & GARP transcription factor (AY048688) \\
\hline$\beta C 1-I S 5$ & 175 & $\begin{array}{l}\text { NADH:ubiquinone oxidoreductase } \\
\text { (NM_111180) }\end{array}$ \\
\hline
\end{tabular}

${ }^{\text {a }}$ Putative translation product. gene family indicates that SIUBC3 is most closely related to subgroup VI members AtUBC28 (Fig. 1), AtUBC10, and AtUBC8, which have all been demonstrated to function as ubiquitin E2 enzymes. SIUBC3 was also found to be highly homologous to the translation products of a functional UBC(E2) enzyme gene from cotton, GhUBC1 (Fig. 1). UBC proteins contain a conserved ubiquitin-conjugating domain (UBCd) between amino acids 4 and 136. This domain contains a UBC active site, FHPNINSNGSICLDIL (amino acids 74 to 89), in which Cys 85 has been identified as the acceptor site for ubiquitin (Sung et al. 1990).

To confirm that SIUBC3 is a functional UBC enzyme, a fulllength cDNA was cloned into the yeast expression vectors, pCM188 (centromeric plasmid) and pCM190 (multicopy plasmid), and transformed into a yeast strain defective in the yeast UBC enzyme genes, $\mathrm{Sc} U B C 4$ and $S c U B C 5$. The growth rate of the $u b c 4$ and $u b c 5$ single mutants was similar to the wild-type (wt) yeast strain but the $u b c 4 / u b c 5$ double mutant exhibited markedly reduced growth on YPG (1\% yeast extract, $2 \%$ peptone, $3 \%$ glycerol) medium (Fig. 2). However, $u b c 4 / u b c 5$ yeast cells transformed with SIUBC3 grew at a rate comparable with wt yeast and this growth was considerably greater than for the

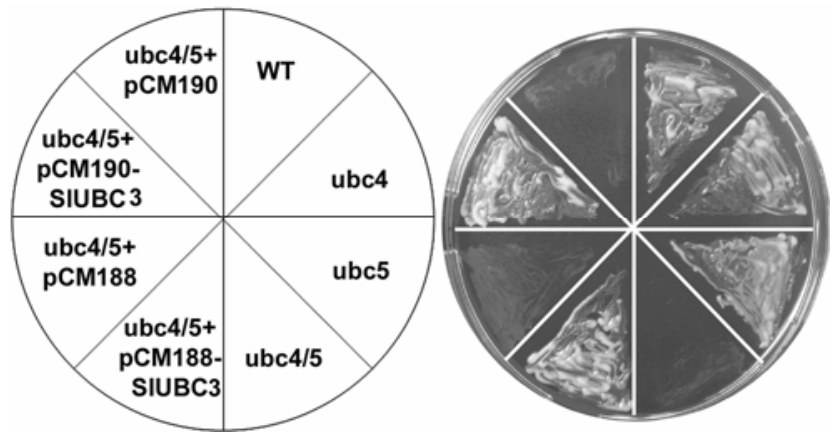

Fig. 2. Complementation assay in yeast $u b c 4 / u b c 5$ by $S I U B C 3$. The yeast $u b c 4 / u b c 5$ double mutant was individually transformed with pCM188, pCM188-SIUBC3, pCM190, or pCM190-SIUBC3. These transformants were streaked with wild-type (WT), $u b c 4, u b c 5$, and $u b c 4 / 5$ yeast on YPG ( $1 \%$ yeast extract, $2 \%$ peptone, $3 \%$ glycerol) media. The location of yeast strains on the plate is shown in the diagram (left). The photograph was taken after 2 days of incubation at $30^{\circ} \mathrm{C}$.

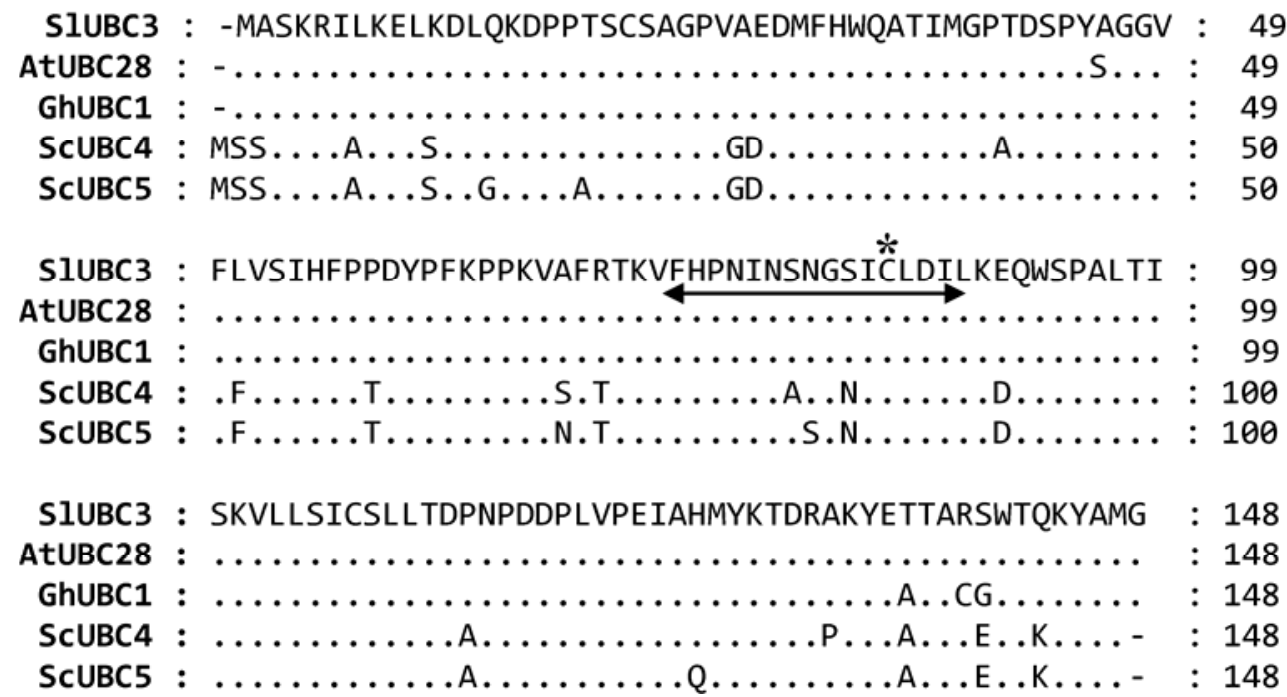

Fig. 1. Alignment of the putative translation product of SIUBC3 with those of other plant ubiquitin-conjugating (UBC) enzyme genes. The alignment was generated by CLUSTALW using default parameters. Database accession numbers: tomato, SIUBC3 (FJ429328); cotton, GhUBC1 (AAL99219); Arabidopsis, AtUBC28 (NP_564828); yeast, ScUBC4 (NP_009638) and ScUBC5 (NP_010344). The UBC active site is underlined and an asterisk indicates the position of the cysteine residue identified as the acceptor site for ubiquitin. 
untransformed double mutant or the double mutant transformed with empty expression vectors. This indicates that SIUBC3 can functionally complement the ScUBC4 and ScUBC5 proteins in yeast.

\section{In vitro binding of SIUBC3 to $\beta C 1$ protein.}

The specificity of the interaction of $\beta C 1$ with SIUBC3 was examined using an in vitro pull-down assay as described by Selth and associates (2005). A purified 6xHis- $\beta$ C1 fusion protein was incubated with crude protein extracted from Escherichia coli cells expressing an SIUBC3-calmodulin-binding peptide (CBP) fusion protein containing a FLAG epitope (CBP-SIUBC3). The His-tagged protein was captured using Ni-NTA and the identity of interacting proteins determined by using antibodies directed against both the polyHis and FLAG epitopes (Fig. 3). A 6xHis-tagged chloramphenicol acetyltransferase (6xHis-CAT) construct was also included as a negative control for protein binding.

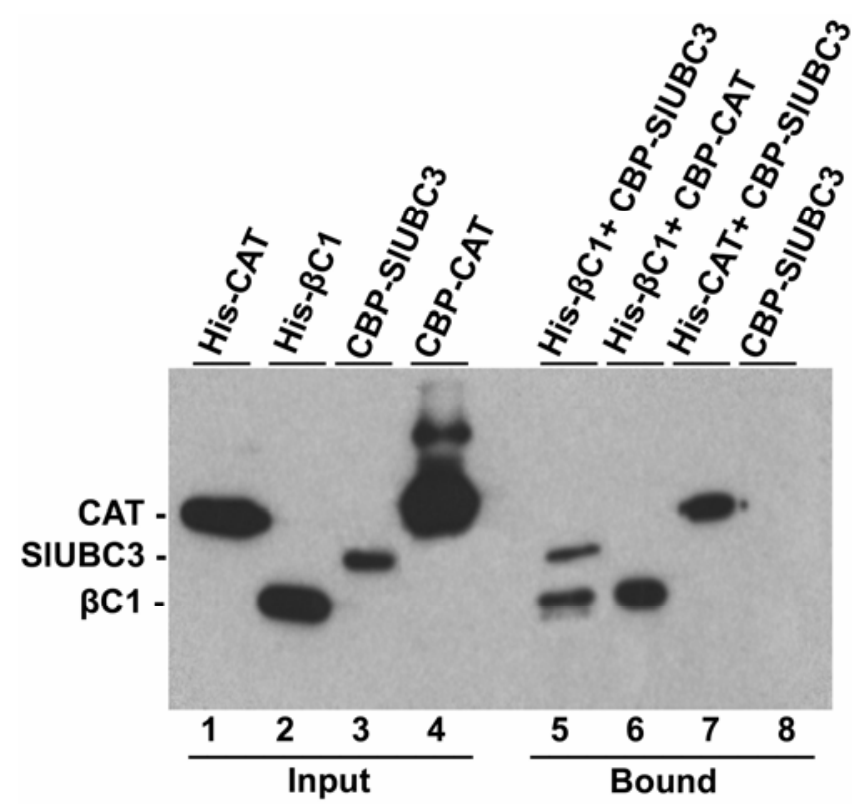

Fig. 3. In vitro binding assay for interaction between $\beta C 1$ and SIUBC3. Crude protein samples from cells expressing polyHis-tagged and calmodulin-binding peptide (CBP)-tagged proteins were mixed, incubated with NiNTA agarose, and washed extensively to remove unbound protein. Protein inputs for each reaction are shown: lane 1, 6xHis-chloramphenicol acetyltransferase; lane 2 , 6xHis- $\beta C 1$; lane 3 , CBP-SIUBC3; and lane $4, \mathrm{CBP}-$ CAT. Bound protein was resuspended in loading buffer, resolved by sodium dodecyl sulfate polyacrylamide gel electrophoresis, and detected by immunoblotting using anti-polyHis and anti-FLAG (CBP-tagged proteins also contain a FLAG epitope) antibodies. Binding reactions were as follows: lane $5,6 \times$ His- $\beta C 1$ and $C B P-S I U B C 3$; lane 6 , 6xHis- $\beta C 1$ and $C B P-$ CAT; lane 7, 6xHis-CAT and CBP-SIUBC3; and lane 8, CBP-SIUBC3 alone. All reactions were performed at least twice with consistent results.
The input recombinant proteins were successfully detected using anti-His and anti-FLAG antibodies (Fig. 3, lanes 1 to 4). Incubation of an extract containing CBP-SIUBC3 and purified $6 \times$ His- $\beta C 1$ resulted in the co-precipitation of both proteins (Fig. 3, lane 5). In contrast, incubation of CBP-SIUBC3 with either purified 6xHis-CAT protein (Fig. 3, lane 7) or Ni-NTA resin alone (Fig. 3, lane 8) did not result in pull down of the CBP-SIUBC3 protein, indicating that the interaction of CBPSIUBC3 is specific for $6 x$ His- $\beta C 1$. To confirm that $6 x$ His- $\beta C 1$ was interacting specifically with the S1UBC component of the CBP-SIUBC3 fusion protein, a further treatment was carried out in which purified $6 x$ His- $\beta C 1$ was incubated with total soluble protein extracted from cells induced to express CBPCAT. No CBP-CAT was detectable in the bound fraction (Fig. 3 , lane 6), confirming that there is a specific interaction between $\beta C 1$ and SIUBC3 in vitro.

\section{SIUBC3 and $\beta C 1$ interaction in planta.}

To investigate whether an interaction between SIUBC3 and $\beta C 1$ is feasible in plant cells, the relative subcellular localization of $\beta C 1$ :GFP and SIUBC3:GFP fusion proteins was examined following biolistic delivery into $N$. benthamiana epidermal cells. In contrast to free GFP (Fig. 4C), which was distributed within the cytoplasm, cell periphery, and nucleus, both $\beta C 1$ :GFP and SIUBC3:GFP were only found in the nucleus and at the cell periphery (Fig. 4A and B), indicating that an opportunity exists for physical interaction between these two proteins in DNA $\beta$-infected plants.

To further verify the interaction between $\beta C 1$ and SIUBC3 in planta, a bimolecular fluorescence complementation (BiFC) assay (Hu et al. 2002; Stolpe et al. 2005) was employed. Fusions were constructed between the N-terminal (YN; 1 to 154 amino acids) and C-terminal (YC; 155 to 238 amino acids) components of yellow fluorescent protein (YFP) and the SIUBC3 and $\beta C 1$ proteins and the constructs bombarded into mustard (Sinapis alba L.) hypocotyl cells. YFP signals were only observed in hypocotyl cells co-bombarded with plasmid constructs expressing $\beta C 1-Y C$ and SIUBC3-YN (Supplementary Fig. S1, panel a). The H2B-YFP fusion protein, a control for YFP visualization, produced yellow fluorescence in the nucleus (Boisnard-Lorig et al. 2001). In contrast, no YFP signal was observed when $\beta \mathrm{C} 1-\mathrm{YC}$ was co-bombarded with the Tomato leaf curl virus (ToLCV) C4-YN fusion protein. Similar results were also obtained using the fusion proteins in the alternative configuration (i.e., $\beta \mathrm{C} 1-\mathrm{YN}$ and SIUBC3-YC) (data not shown). These results confirm that the $\beta C 1$ protein interacts with SIUBC3 in planta.

\section{Interaction of SIUBC3 with $\beta C 1$ proteins from other DNA $\beta$ molecules.}

To investigate whether other $\beta \mathrm{C} 1$ proteins are able to interact with the SIUBC3 protein, two different $\beta C 1$ proteins encoded by DNA $\beta$ associated with ToLCV (ToLCV- $\beta C 1$ ) and Okra
BC1:GFP

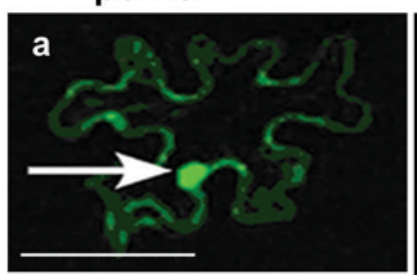

SIUBC3:GFP

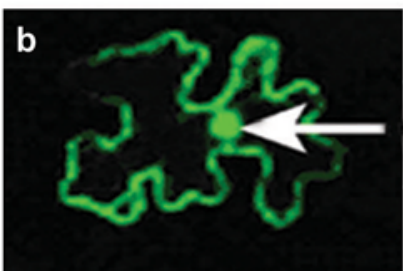

GFP

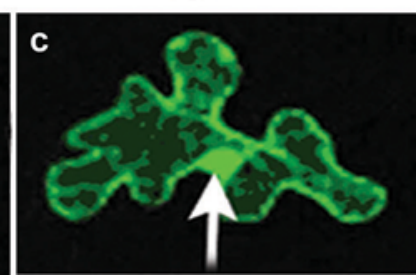

Fig. 4. Subcellular localisation of $\beta C 1$ and SIUBC 3 in the epidermal cells of Nicotiana benthamiana. a, $\beta C 1$ :green fluorescent protein (GFP) and b, SIUBC3:GFP were transiently expressed under the Cauliflower mosaic virus $35 \mathrm{~S}$ promoter in $N$. benthamiana epidermal cells. c, A control for subcellular localization, GFP, is also shown in $N$. benthamiana epidermal cells. The cell nucleus is indicated by an arrow. Cells were analyzed for GFP fluorescence by confocal microscopy. Bar $=50 \mu \mathrm{m}$ 
leaf curl virus (OLCV- $\beta \mathrm{C} 1)$ were used in $\mathrm{Y} 2 \mathrm{H}$ assays with SIUBC3. ToLCV- $\beta C 1$, which shows $97 \%$ homology to CLCuMV- $\beta C 1$ protein, successfully interacted with SIUBC3 (Fig. 5B, lane 3 ) whereas OLCV- $\beta \mathrm{C} 1$, which only shows $41 \%$ homology to CLCuMV- $\beta C 1$ protein, did not interact with SIUBC3 (Fig. 5B, lane 2). Immunoblot analysis of yeast cells demonstrated that the noninteracting pLex- $\beta C 1$ from OLCV DNA $\beta$ was expressed at similar levels compared with pLex$\beta C 1$ from ClCuMV DNA $\beta$ (Fig. 5A), confirming that the lack of interaction was not due to an absence of this protein in the $\mathrm{Y} 2 \mathrm{H}$ assay.

\section{A myristoylation-like motif of $\beta \mathrm{C} 1$ is required for interaction with SIUBC3.}

Analysis of the $\beta C 1$ protein using the Prosite database predicts the presence of two $\alpha$-helices between amino acids 62 and 75 and 78 and 95 and a myristoylation-like motif (GMDVNE) located between amino acids 103 and 108 (Fig. $6 \mathrm{~A})$. The importance of these predicted domains within the $\beta C 1$ protein for interaction with SIUBC3 was tested in the $\mathrm{Y} 2 \mathrm{H}$ assay. Immunoblot analysis of protein expression showed that all of the deletion mutants of pLex- $\beta C 1$ were expressed at levels similar to that of the pLex full-length $\beta \mathrm{C} 1$ (Fig. 6B). Deletions encompassing the first 55 amino acids of the $\beta C 1$ protein (Fig. 6A) had no effect on the interaction with SIUBC3 (Fig. 6C). In contrast, deletion of a 39-amino-acid region encompassing the predicted myristoylation-like motif and a single $\alpha$-helix motif from the C-terminus of $\beta C 1\left(\beta C 1_{1-78}\right)$ significantly impaired the interaction with the full-length SIUBC3 in the yeast system (Fig. 6C). Similar results were obtained with deletion of the C-terminal 16 amino acid region $\left(\beta C 1_{1-103}\right)$

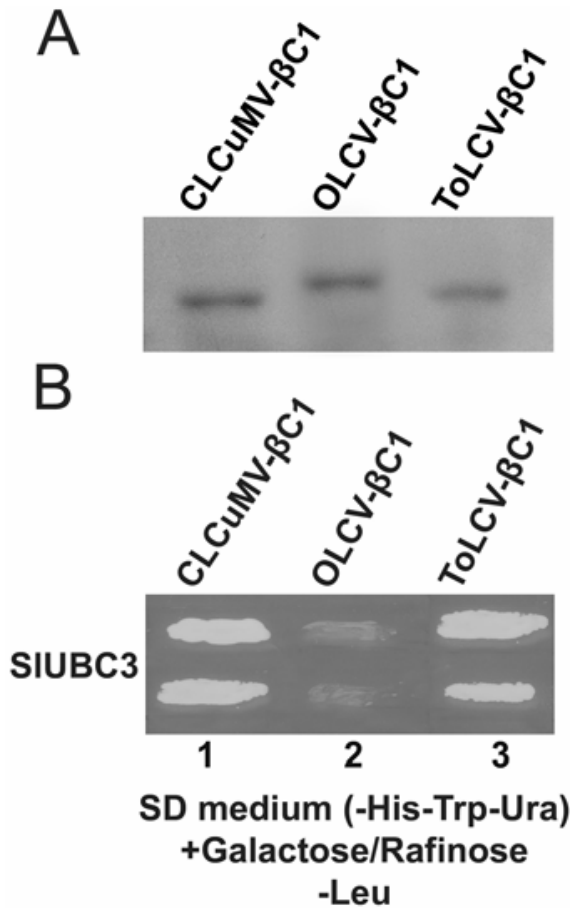

Fig. 5. SIUBC3 interaction with $\beta C 1$ proteins encoded by various DNA $\beta$ components in yeast. A, Immunoblot analysis showing relative levels of different $\beta C 1$-LexA fusion proteins expressed in yeast as detected with an anti-LexA antibody. B, Yeast co-expressing SIUBC3 and either $\beta C 1$ encoded by lane 1, Cotton leaf curl Multan virus (CLCuMV) DNA $\beta$; lane 2, Okra leaf curl virus (OLCV) DNA $\beta$; or lane 3, Tomato leaf curl virus (ToLCV) DNA $\beta$ was grown on SD-His-Trp-uracil (Ura) medium, and interactions were tested by leucine prototrophy on an inductive carbon source (galactose and raffinose). $\beta C 1$ genes were fused to the LexA DNA binding domain, whereas SIUBC3 was fused to the B42 activation domain. containing the predicted myristoylation-like motif alone (Fig. $6 \mathrm{C})$. However, a $\beta \mathrm{C} 1$ construct $\left(\beta \mathrm{C} 1_{1-108}\right)$ in which only the last $11 \mathrm{C}$-terminal amino acids were deleted, leaving the myristoylation-like motif intact, interacted strongly with the SIUBC3 protein (Fig. 6C). These results clearly point to a role for the predicted myristoylation-like motif of $\beta \mathrm{C} 1$ in the interaction with SIUBC3.

Myristoylation is a post-translational modification of proteins that involves the covalent attachment of a fatty acid myristate
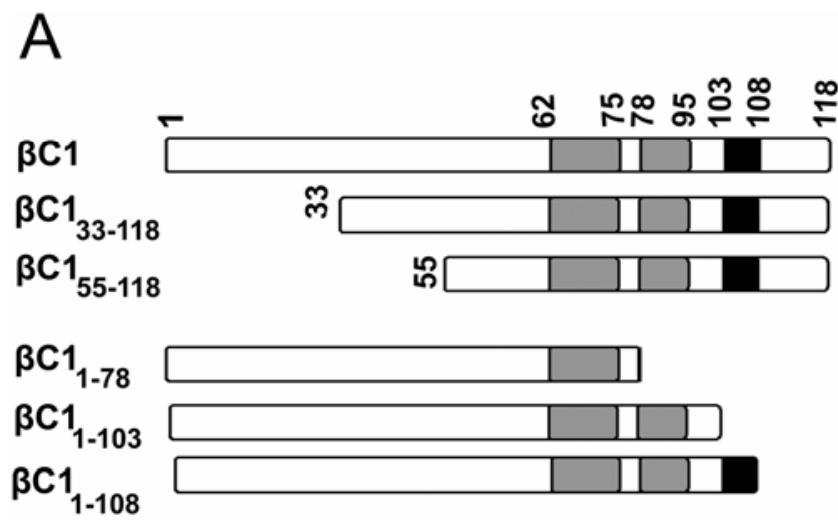

B

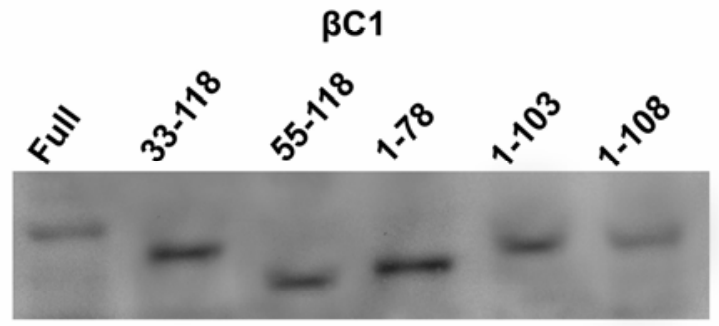

$\mathcal{C}$
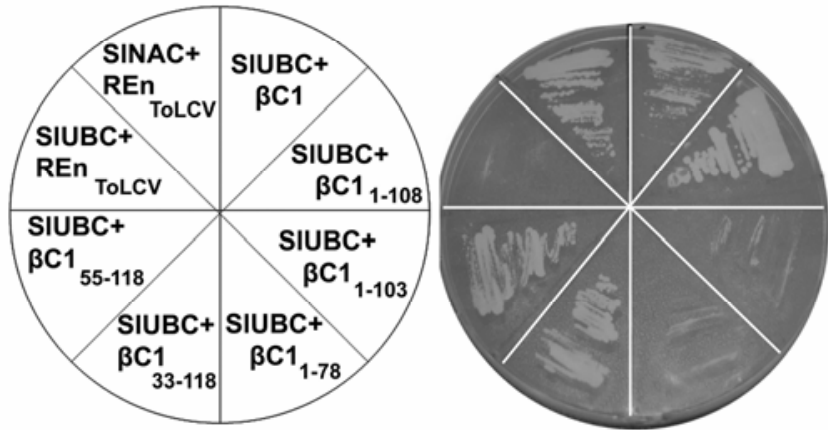

Fig. 6. Domains of the $\beta C 1$ protein that interact with intact SIUBC3 in the yeast system. Deletion mutants of $\beta C 1$ proteins were expressed as LexA DNA binding domain fusions. The SIUBC3 protein was expressed as a pB42 activation domain fusion. A, Diagrammatic representation of predicted domains and also deletion mutants of $\beta \mathrm{C} 1$ protein. The myristoylation-like motif is shown in black and two $\alpha$-helices motifs are shown in gray boxes. Numbers indicate the position of each motif in the $\beta \mathrm{C} 1$ protein. B, Immunoblot analysis showing relative levels of full-length and deletion mutant $\beta C 1$-LexA fusion proteins expressed in yeast as detected with an anti-LexA antibody. $\mathbf{C}$, Yeast co-expressing SIUBC3 and $\beta C 1$ deletion mutants was grown on SD-His-Trp-Ura medium, and the interaction was tested by leucine prototrophy on an inductive carbon source (galactose and raffinose). For a positive control, Tomato leaf curl virus (ToLCV) REn and SINAC were co-expressed in yeast. For the negative control, ToLCV REn and SIUBC3 were used. 
group to the polypeptide, most commonly glycine (Boutin 1997). The role of the G103 residue in the interaction with SIUBC3 was analyzed with two $\beta C 1$ mutant constructs containing either a single G103A mutation ( $\beta \mathrm{C} 1$ mut1) or a triple G103A, M104K, and E108W mutation ( $\beta C 1$ mut2) of the myristoylation-like motif (Fig. 7A). Both mutant proteins were expressed in yeast at a level similar to the intact $\beta \mathrm{C} 1$ protein (Fig. 7B); however, neither of the mutant constructs interacted with SIUBC3 in the $\mathrm{Y} 2 \mathrm{H}$ assay (Fig. 7C). These results indicate that the G103 residue in the myristoylation-like motif of $\beta C 1$ is crucial for the interaction with SIUBC3.

\section{A myristoylation-like motif is required}

\section{for DNA- $\beta$-specific symptom development.}

Deletion mutants (Fig. 6) and site-directed mutagenesis studies (Fig. 7) of the myristoylation-like motif in $\beta C 1$ indicate that this motif is required for interaction of $\beta \mathrm{C} 1$ protein with SIUBC3 in the yeast system. To investigate whether this myristoylation-like motif is also important for DNA- $\beta$-specific symptom production, $N$. benthamiana and $N$. tabacum plants were agroinoculated with ToLCV alone or ToLCV together with either wt DNA $\beta$ or a DNA $\beta-$ G103A mutant.

Dot blot assays confirmed that both the wt DNA $\beta$ and the DNA $\beta$-G103A mutant replicated to similar levels in the newly emerging $N$. benthamiana and $N$. tabacum leaves (Fig. 8A). Sequencing of polymerase chain reaction (PCR) products amplified from total nucleic acid extracted from systemically infected leaves confirmed that the G103A mutation in the myristoylation-like motif was maintained in plants infected with the DNA $\beta-G 103 A$ mutant. Northern blot assay also confirmed that $\beta C 1$ was expressed at similar levels in plants infected with either wt DNA $\beta$ or DNA $\beta$ mutant (Fig. $8 B$ ).

Although the G103A mutation had no effect on replication or spread of the DNA $\beta$ molecule, there was a clear change in DNA- $\beta$-mediated symptom development. Plants co-infected with ToLCV + wt DNA $\beta$ displayed typical DNA- $\beta$-specific symptoms such as downward leaf curling in $N$. benthamiana (Fig. 8C, panel c). In contrast, plants co-infected with ToLCV and the DNA $\beta$-G103A mutant failed to produce DNA- $\beta$-specific symptoms and, instead, showed symptoms typical of infection with ToLCV alone, including stunting and upward leaf curling in $N$. benthamiana (Fig. 8C; compare panels b and d). Similar results were obtained with $N$. tabacum. Plants infected with ToLCV and DNA $\beta$ (Fig. 8D, panel c) showed severe leaf wrinkling, vein swelling, and darkening, whereas these DNA$\beta$-specific symptoms were absent in plants infected with ToLCV and DNA $\beta$ mut. These plants showed only mild leaf wrinkling symptoms which are typical of plants infected with ToLCV alone (Fig. 8D; compare panels $b$ and d). These results demonstrate that the myristoylation-like motif and, in particular, the G103 residue of this motif is required for induction of DNA- $\beta$-specific symptoms in host plants.

\section{Accumulation of polyubiquitinated proteins \\ in transgenic tobacco plants expressing $\beta C 1$.}

It has been proposed that the UBC enzyme catalyzes the formation of the polyubiquitin chain (Chen and Pickart 1990) that is added to substrate proteins for recognition by the $26 \mathrm{~S}$ proteasome (Pickart 2001). To test whether interaction of $\beta C 1$ protein with SIUBC3 affects the level of polyubiquitinated proteins, soluble proteins were extracted from three individual wt tobacco and transgenic $35 \mathrm{~S}-\beta \mathrm{C} 1$ tobacco plants and separated on polyacrylamide gel, and the quantity of polyubiquitinated proteins was estimated by Western blot using a mouse antiubiquitin monoclonal antibody. The level of high molecular weight immunoreactive materials, presumed to be polyubiquitinated proteins, detected in protein extracts from wt tobacco plants (Fig. 9B, lanes 1 to 3) was found to be markedly higher than that extracted from transgenic $35 \mathrm{~S}-\beta \mathrm{C} 1$ plants (Fig. 9B, lanes 4 to 6 ), which is consistent with a $\beta \mathrm{C} 1$-mediated reduction in polyubiquitination activity.

\section{DISCUSSION}

\section{Interaction of $\beta C 1$ with host SIUBC3 is required for symptom induction.}

DNA $\beta$ components associated with some monopartite Begomovirus spp. have previously been shown to be important for disease symptom induction in certain host species (Briddon et al. 2001; Saunders et al. 2000). Furthermore, it has been established that the symptoms associated with DNA $\beta$ are mediated through the $\beta C 1$ gene (Cui et al. 2004; Qazi et al. 2007; Qian and Zhou 2005; Saeed et al. 2005; Saunders et al. 2004). In this study, we provide evidence that $\beta \mathrm{C} 1$-dependent symptom development is required for the interaction of $\beta C 1$ with a host UBC. The interaction of $\beta C 1$ with SIUBC3 was demonstrated in both an in vitro protein binding assay using recombinant proteins and in vivo using a BiFC assay.

SIUBC3 was demonstrated to be a functional UBC protein by complementation of a yeast $u b c 4 / 5$ mutant (Fig. 2) rather than functioning as a sumoylation conjugative enzyme (Supplementary Fig. S2). UBC plays a major role in the ubiquitin
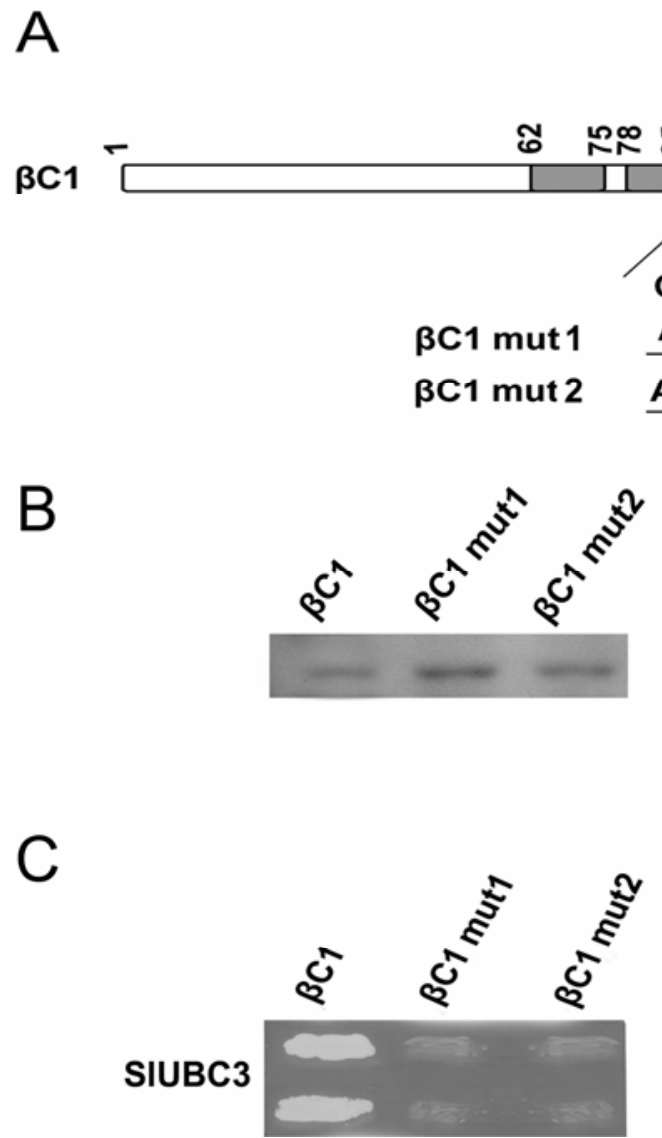

Fig. 7. $\beta C 1$ interacts with SIUBC3 via a myristoylation-like motif in the yeast system. A, Diagram showing the sequence of the predicted myristoylation-like motif in the $\beta C 1$ protein. Mutated residues are underlined. B, Immunoblot analysis showing relative levels of wild-type and mutant $\beta C 1$ LexA fusion proteins expressed in yeast as detected with an anti-LexA antibody. C, Yeast two-hybrid assays testing the ability of site-directed mutants of $\beta \mathrm{C} 1$ to interact with the intact SIUBC3. Yeast co-expressing SIUBC 3 and either $\beta C 1$ or $\beta C 1$ mutant proteins were grown on SD-HisTrp-Ura medium, and the interaction was tested by leucine prototrophy on an inductive carbon source (galactose and raffinose). 
proteasome pathway which is responsible for the selective degradation of abnormal and short-lived regulatory proteins, including transcription factors, cell cycle proteins, and signal transducers, and, hence, plays a central role in many eukaryotic cellular processes (Jentsch 1992; Laney and Hochstrasser 1999; Moon et al. 2004). Thus, interaction between the E2, E3, and target protein is required to facilitate this ubiquitination step (Supplementary Fig. S3A). Attachment of a chain of ubiquitin
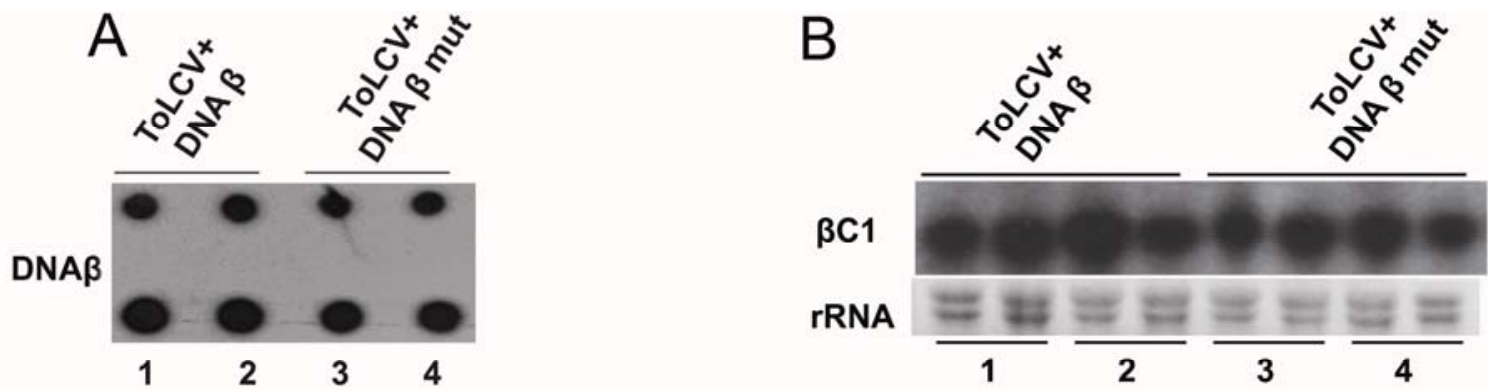

C

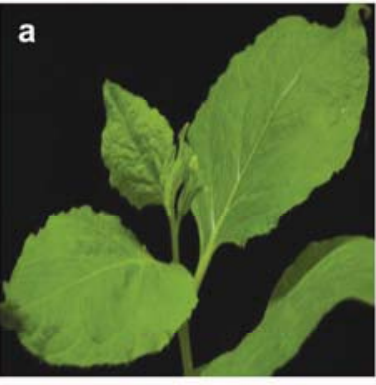

Noninfected

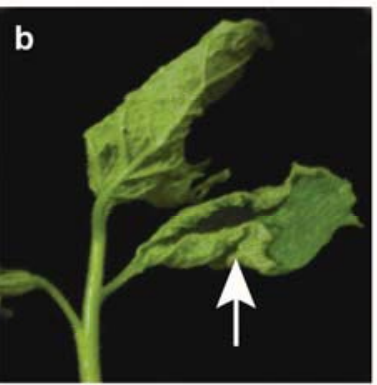

ToLCV

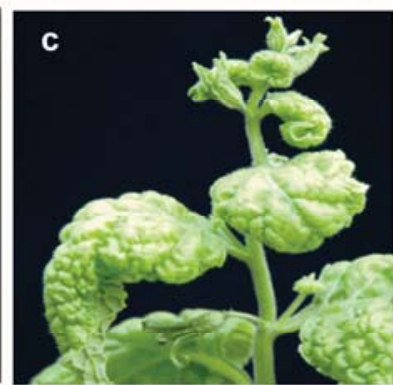

ToLCV+ DNA $\beta$

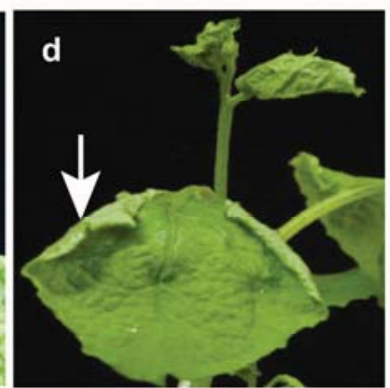

ToLCV+ DNA $\beta$ mut

D
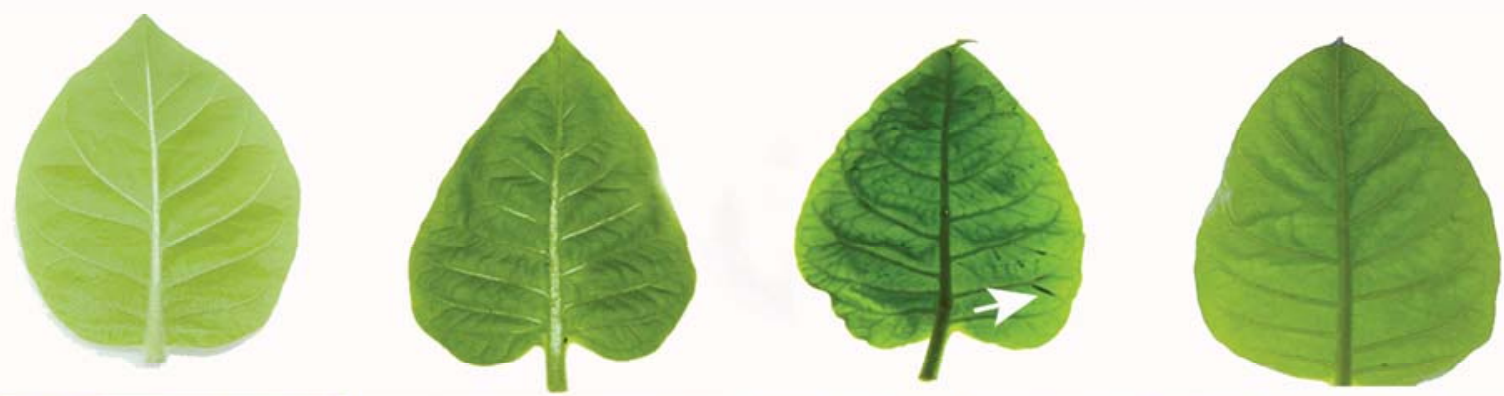

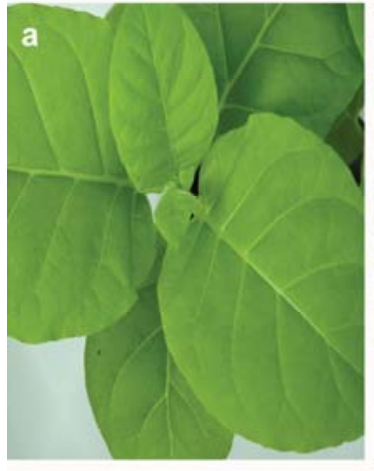

Noninfected

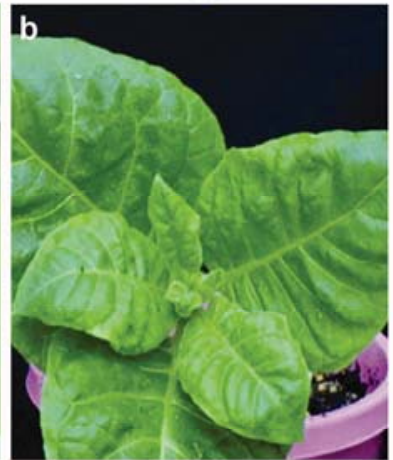

ToLCV

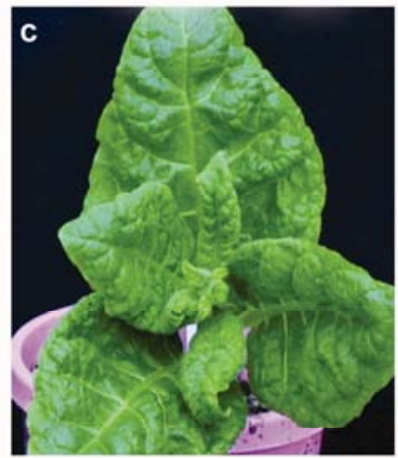

$T o L C V+D N A \beta$

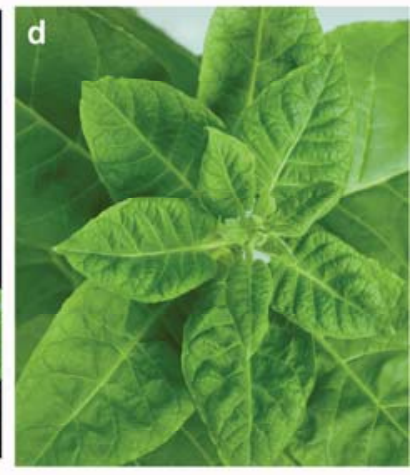

ToLCV+ DNA $\beta$ mut

Fig. 8. Effect of mutation in the myristoylation-like motif of $\beta C 1$ on the DNA- $\beta$-specific symptoms in infected plants. A, Dot blot assay using a full-length DNA $\beta$ as a probe showing replication of DNA $\beta$ in newly emerging leaves of Nicotiana benthamiana (upper row) and $N$. tabacum (lower row) plants infected with Tomato leaf curl virus (ToLCV) and either lanes 1 and 2, DNA $\beta$; or lanes 3 and 4, DNA $\beta$ mut. Results are shown for two selected plants. B, Northern blot assay using the $\beta C 1$ gene as a probe to show expression of $\beta C 1$ in newly emerging leaves of lanes 1 and $3, N$. benthamiana and lanes 2 and 4 , N. tabacum plants infected with ToLCV and either lanes 1 and 2, DNA $\beta$ or lanes 3 and 4, DNA $\beta$ mut. C, $N$. benthamiana plants infected with ToLCV alone (b) or in combination with DNA $\beta$ (c) or DNA $\beta$ mut (d). Arrows indicate upward leaf curling. D, N. tabacum plants infected with ToLCV alone (b) or in combination with DNA $\beta$ (c) or DNA $\beta$ mut (d). Arrow indicates vein swelling and darkening. This experiment was repeated using 12 plants for each treatment with the same results. Pictures were taken 28 days after inoculation. 
molecules to the target protein is required for recognition by the 26S proteasome (Pickart 2001).

Targeting and modification of the host ubiquitination system is an emerging theme in virus research. It has been shown that many human viruses have evolved a strategy to exploit or manipulate the host ubiquitin-proteasome pathway for their infection cycle (Gao and Luo 2006). A number of DNA $\beta$ satellites have been shown to induce specific symptoms in host plants (Briddon and Stanley 2006; Briddon et al. 2003; Rojas et al. 2005). Significantly, SIUBC3 was shown to interact in the $\mathrm{Y} 2 \mathrm{H}$ system with $\beta \mathrm{C} 1$ proteins of DNA $\beta$ satellites associated with CLCuMV and ToLCV which produce symptoms in $N$. benthamiana plants. In contrast, SIUBC3 did not interact with the $\beta C 1$ protein of OLCV DNA $\beta$ which does not produce symptoms in N. benthamiana plants (Briddon et al. 2003), further supporting the hypothesis that $\beta C 1$ interaction with SIUBC3 and modification of the host ubiquitination system is required for $\beta \mathrm{C} 1$ pathogenesis.

\section{A myristoylation-like motif in $\beta \mathrm{C} 1$ is required for pathogenicity.}

Myristoylation is an irreversible post-translational lipid modification of proteins that leads to addition of a myristate molecule to an amino acid residue, which is normally a glycine residue located at the N-terminal end of the polypeptide. However, the myristoylation motif was also predicted at an internal site rather than at the $\mathrm{N}$-terminus in over 300 Arabidopsis proteins (Podell and Gribskov 2004). It is thought that the myristoylation is important for biological activity of some lower and higher eukaryotic proteins (Boutin 1997). For example, the Nmyristoylation motif of AC4 encoded by East African cassava mosaic Cameroon virus (EACMCV) was shown to be required for viral pathogenicity (Fondong et al. 2007). Here, we show that mutation of a specific G103 residue within a predicted myristoylation-like motif of CLCuMV $\beta C 1$ protein not only prohibited interaction with the SIUBC3 in yeast (Fig. 7) but also suppressed the development of DNA- $\beta$-induced symptoms in host plants (Fig. 8).

Further support for the importance of the myristoylationlike motif of CLCuMV- $\beta C 1$ in the induction of disease symptoms comes from observations with naturally occurring DNA $\beta$ mutants. The DNA $\beta$ mutant, CLCD $\beta \Delta 01-P a k$, which contains a truncated $\beta C 1$ protein in which the myristoylation-like motif has been maintained, induces DNA- $\beta$-specific symptoms in both $N$. benthamiana and cotton (Briddon et al. 2003). In contrast, a DNA $\beta$ associated with hibiscus leaf curl disease (HLCD $\beta 01-P a k$ ) in which the C-terminal domain containing the myristoylation-like motif has been deleted does not induce DNA- $\beta$-specific symptom in host plants (Briddon et al. 2003).

Although our data strongly support a role for the myristoylation-like motif in mediating the interaction with SIUBC3, other data suggest that this may not be the only domain within $\beta C 1$ that is required for this interaction. OLCV- $\beta C 1$ contains a myristoylation-like motif identical to CLCuMV- $\beta C 1$ but no evidence of interaction between OLCV- $\beta C 1$ and SIUBC3 was obtained in the $\mathrm{Y} 2 \mathrm{H}$ assay (Fig. 5). Furthermore, Briddon and associates (2003) have previously shown that, in contrast to CLCuMV DNA $\beta$ (Fig. 8), OLCV DNA $\beta$ does not produce specific symptoms in $N$. benthamiana plants. Given the significant differences in the amino acid sequence between OLCV$\beta C 1$ and $C L C u M V-\beta C 1$ in the regions outside of the myristoylation-like motif (38.5\% amino acid identity), we suggest that other regions of the $\beta \mathrm{C} 1$ protein must also influence the interaction of the myristoylation-like motif with SIUBC3. It is conceivable, for example, that the overall sequence of the $\beta \mathrm{C} 1$ protein will significantly modify the tertiary structure of the protein and, in so doing, affect the presentation or availability of the myristoylation-like motif for binding.

Myristoylation is also thought to alter the ability of a protein to interact with membranes or the hydrophobic domains of other proteins and thereby influence the targeting of the protein to the plasma membrane, endoplasmic reticulum, mitochondrion, or other membrane system (Podell and Gribskov 2004). However, this does not appear to be the case with $\beta C 1$ because mutation of G103A had no effect on the localization of this protein to the cell periphery and the nucleus (data not shown).

\section{Effects of $\beta C 1$ on the ubiquitin proteasome pathway.}

Having established that CLCuMV DNA- $\beta$-induced symptom development appears to be mediated through the direct interaction of $\beta \mathrm{C} 1$ protein with host UBC protein, the question remains as to how this interaction might lead to the development of symptoms in plants. One possibility is that the interaction between $\beta C 1$ protein and SIUBC3 somehow causes an increase in the level of DNA $\beta$ replication, resulting in enhanced symptom development. Several geminiviral-host interactor factors have been shown to enhance the replication level of the virus (Nagar et al. 1995; Selth et al. 2005; Settlage et al. 2001). However, overexpression of SIUBC3 in a transient replication assay appeared to have no significant effect on the level of accumulation of DNA $\beta$ (Supplementary Fig. S4B). Thus, despite the importance of the ubiquitin proteasome system and UBC in regulation of the cell cycle (Deshaies 1995; Devoy et al. 2005) which, in turn, is important for Geminivirus replication, interaction of $\beta \mathrm{C} 1$ with SIUBC3 appears to have no direct effect on DNA $\beta$ replication. This finding is also consistent

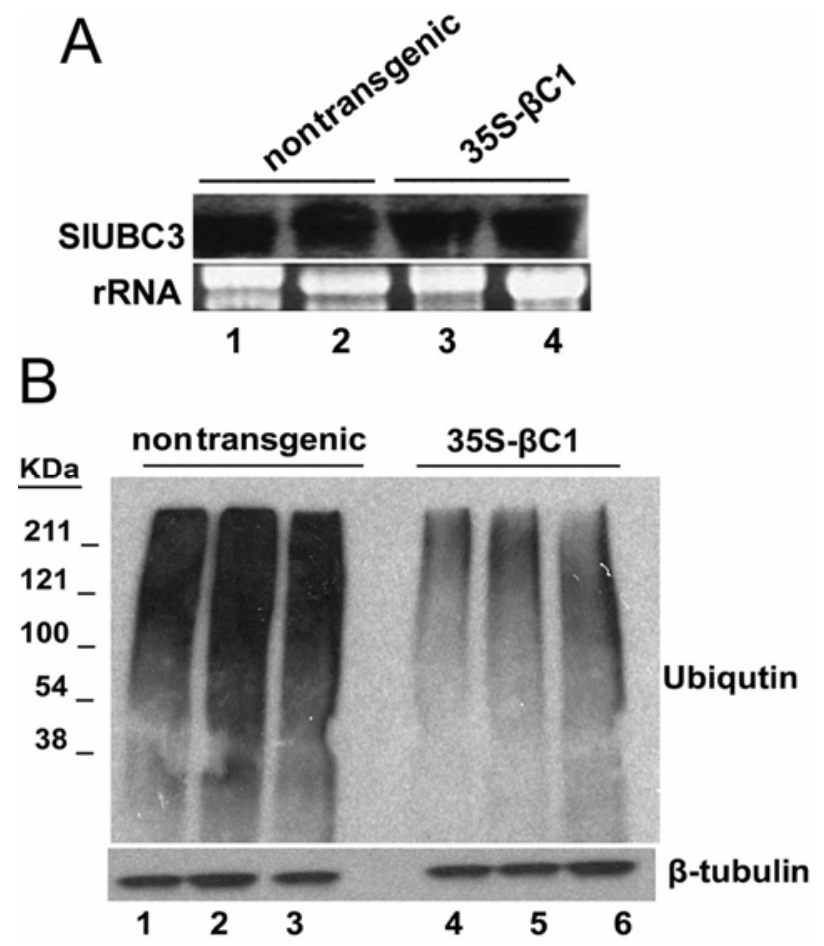

Fig. 9. Analysis of the $S I U B C 3$ expression and the accumulation of polyubiquitinated proteins in $35 \mathrm{~S}-\beta \mathrm{C} 1$ transgenic tobacco plants. A, RNA gel blot showing the expression of the homologous $S I U B C 3$ in lanes 1 and 2 , wild-type and lanes 3 and $4,35 \mathrm{~S}-\beta \mathrm{C} 1$ transgenic tobacco plants. The rRNA indicates the relative quantities of the RNA analyzed. B, Polyubiquitination level of protein extracted from lanes 1 to 3 , wild-type tobacco plants compared with lanes 4 to 6 , protein extracted from $35 \mathrm{~S}-\beta \mathrm{C} 1$ transgenic plants using a mouse antiubiquitin monoclonal antibody. Total protein was extracted from individual plants and the same amount of protein was used. A molecular weight protein ladder is shown on the left. 
with the dispensable role of $\beta \mathrm{C} 1$ in DNA $\beta$ replication (D. $\mathrm{Li}$, unpublished data) (Tao and Zhou 2004).

UBC has an important role in the generation of the polyubiquitin chain that must be linked to a substrate for recognition by the 26S proteasome (Pickart 2001), and ScUBC4 and ScUBC5 enzymes from yeast were shown to generate high molecular weight ubiquitin-protein conjugates in vivo (Seufert and Jentsch 1990). Because SIUBC3 complements the yeast $u b c 4 / u b c 5$ mutant (Fig. 2), it could be expected that SIUBC3 would have a similar function in plants. Expression of $\beta \mathrm{C} 1$ in transgenic tobacco was found to result in a decreased level of polyubiquitinated proteins compared with that in wt plants (Fig. 9B). This decrease could not be attributed to a decrease in SIUBC3 expression in these plants (Fig. 9A). One possibility is that the interaction of $\beta C 1$ with SIUBC 3 impairs the activity of this UBC, resulting in a perturbation in the ubiquitin proteasome pathway. Yang and associates (2008) have recently shown that $\beta \mathrm{C} 1$ protein encoded by Tomato yellow leaf curl China virus (TYLCCNV) DNA $\beta$ is an unstable protein which can be targeted for degradation by $26 \mathrm{~S}$ proteasomes in plant cells. Therefore, inhibition of the ubiquitin proteasome pathway would result in accumulation of $\beta C 1$ protein in infected plants leading to symptom development. Support for this hypothesis also comes from observations with tobacco mutants in which the ubiquitin pathway has been partially suppressed (Bachmair et al. 1990). Significantly, in these ubiquitin-pathway-impaired transgenic plants, the observed phenotypic characteristics include downward leaf curling, stunting, and abnormal vascular tissue and are very similar to the DNA- $\beta$-specific symptoms observed in $N$. benthamiana (Fig. 8) and the phenotypes of transgenic tobacco plants expressing 35S- $\beta C 1$ (Saeed et al. 2005; Saunders et al. 2004).

Recently, Yang and associates (2008) reported on the results of experiments involving the use of the model plant Arabidopsis thaliana to try and identify plant proteins that interact with TYLCCNV DNA $\beta C 1$. They proposed that the phenotypic symptoms observed in transgenic Arabidopsis plants expressing TYLCCNV DNA $\beta C 1$ were the result of an interaction between the $\beta C 1$ protein and the MYB transcription factor, ASYMETRIC LEAVES 1 (AS1). Because A. thaliana is not a natural host to TYLCCNV, it is not possible to determine directly the importance of the $\beta \mathrm{C} 1-\mathrm{AS} 1$ interaction in the development of symptoms during helper-virus-mediated DNA $\beta$ infection. However, it does suggest that a number of different plant factors may be targeted by the $\beta \mathrm{C} 1$ protein during infection.

In conclusion, this study suggests that the symptoms associated with DNA $\beta$ infection may be mediated through an interaction between the $\beta C 1$ protein and the host UBC (E2) enzyme, leading to a disruption of the ubiquitin proteasome pathway.

\section{MATERIALS AND METHODS}

Oligonucleotide sequences used in this study were synthesized by Geneworks (Adelaide, Australia) and are listed in Supplementary Table 1. All PCR products were cloned into pDrive vector (Qiagen, Doncaster, Australia) and transformed into E. coli XL1-Blue cells and sequenced (Australian Genomic Research Facility, Brisbane, Australia) to confirm their identity or integrity before subcloning into other plasmid vectors.

\section{Y2H interaction assays.}

Yeast (Saccharomyces cerevisiae) strain displayYEAST-L (MATo, trp1, his3, ura3, leu2::2 LexAop-LEU2; Display Systems Biotech, Vista, CA, U.S.A.), containing a leucine biosynthesis gene downstream of the DNA recognition sequence for the LexA DNA BD, was used in two-hybrid screening. The $\beta C 1$ gene from a DNA $\beta$ (accession number AJ298903) associated with the cotton leaf curl disease was amplified with primers P1 and $\mathrm{P} 2$ and cloned into pLexA to produce pLexA- $\beta \mathrm{C} 1$. The pLexA- $\beta C 1$ vector was used to screen a population of $p B 42 A D$ plasmids containing a library of tomato (cv. Rio Grande) cDNAs fused to the strong transcriptional activator B42 (provided by G. Martin, Cornell University, Ithaca, NY, U.S.A.) as described previously (Selth et al. 2005).

$\beta C 1$ gene constructs were generated and cloned into pLexA as follows: $\mathrm{N}$-terminal deletion constructs $\beta \mathrm{Cl}_{33-118}$ and $\beta \mathrm{C} 1_{55-}$ 118 were amplified with primers $\mathrm{P} 2 / \mathrm{P} 21$ and $\mathrm{P} 2 / \mathrm{P} 22$; and $\mathrm{C}$-terminal deletion constructs $\beta C 1_{1-108}, \beta C 1_{1-103}$, and $\beta C 1_{1-78}$ were amplified using $\mathrm{P} 1 / \mathrm{P} 23, \mathrm{P} 1 / \mathrm{P} 24$, and $\mathrm{P} 1 / \mathrm{P} 25$ primers, respectively.

Mutation of the myristoylation-like motif of $\beta \mathrm{C} 1$ was undertaken using a site-directed mutagenesis kit (Stratagene, La Jolla, CA, U.S.A.). Primers P18 and P26 were used to introduce a G103A mutation into pLexA- $\beta \mathrm{C} 1$ to produce $\mathrm{pLexA}$ : $\beta C 1$ mut1. Primers P19 and P20 were used to introduce the triple mutation G103A, M104K, and E108W into pLexA- $\beta$ C1 to produce pLexA- $\beta C 1$ mut2.

$\beta C 1$ genes were amplified from other DNA $\beta$ molecules associated with ToLCV (accession number AJ316035) and OLCV (accession number AJ 316029) using P2/P3 and P4/P9 primers, respectively, and cloned into pLexA. Full-length $S I U B C 3$ was cloned into $\mathrm{pB} 42 \mathrm{AD}$ vector to produce $\mathrm{pB} 42-\mathrm{SIUBC} 3$.

Yeast cells were sequentially transformed with pLexA- $\beta C 1$ and pB42-SIUBC3 constructs according to the Yeast Protocols Handbook 2001 (Clontech, Palo Alto, CA, U.S.A.) and colonies were selected on agar plates lacking uracil, histidine, tryptophan, and leucine but containing galactose and raffinose to induce the GAL1 promoter-driving expression of the B42SIUBC3 fusions. These interactions were also tested by $\beta$ galactosidase activity in the yeast system (data not shown).

To test fusion protein production in yeast, total protein $(0.5$ $\mathrm{ml}$ of yeast culture equivalent) was extracted and size fractionated on 14\% (wt/vol) Tris-Gly-sodium dodecyl sulfate (SDS) polyacrylamide gels. Then, protein samples were transferred to Immobilon $\mathrm{P}$ polyvinylidene fluoride (PVDF) membrane (Millipore, Billerica, MA, U.S.A.) and blocked with $5 \%$ (wt/vol) nonfat dry milk before incubation with Mouse AntiLex A Monoclonal Antibody-horseradish peroxidase conjugate (Santa Cruz Biotechnology, Inc., Santa Cruz, CA, U.S.A.) to detect LexA-fusion proteins. The signal was detected using Super-Signal West Pico chemiluminescent substrate (Pierce Biotechnology, Rockford, IL, U.S.A.)

\section{5'-RACE PCR.}

The full-length SIUBC3 open reading frame (ORF) sequence was obtained by 5'-RACE using a GeneRacer kit (Invitrogen). Total RNA extracted from leaf of tomato (cv. Grosse Lisse) and pretreated with calf intestinal phosphatase before being treated with tobacco acid pyrophosphatase. The GeneRacer oligo RNA was ligated to the $5^{\prime}$ end of the mRNA using T4 RNA ligase and reverse transcribed by SuperScript III RT to yield cDNA, which was then used as a template to amplify the 5' end of the SIUBC3 ORF using GeneRacer 5' primer P29 and P10. This PCR product was used to amplify the whole SIUBC3 ORF using P10 and P11 primers.

\section{Yeast complementation assays.}

The functional activity of SIUBC3 was tested in the $S$. cerevisiae ubc4, ubc5, and ubc4/ubc5 mutants provided by $\mathrm{S}$. Jentsch (Purdue University). The SIUBC3 ORF was amplified with primers P10 and P12 and cloned into pCM188 (centromeric plasmid) and pCM190 (multicopy plasmid) vectors 
(Garí et al. 1997) to generate pCM188-SIUBC3 and pCM190SIUBC3. The yeast $u b c 4 / u b c 5$ double mutant was transformed separately with pCM188, pCM188-SIUBC3, pCM190, and pCM190-SIUBC3 and selected on media lacking uracil. Yeast cells were grown at $30^{\circ} \mathrm{C}$ to analyze growth rates.

\section{Production of recombinant proteins and in vitro binding assay.}

His-tagged $\beta \mathrm{C} 1$ and CAT proteins were produced in $E$. coli M15 cells using the $\mathrm{pQE} 30$ vector (Qiagen). The coding region of $\beta C 1$ was amplified using primers $\mathrm{P} 5$ and $\mathrm{P} 6$ and cloned into pQE30 to generate $\mathrm{pQE} 30-\beta \mathrm{C} 1$. pQE30-CAT was constructed in the same way, using primers $\mathrm{P} 7$ and $\mathrm{P} 8$ to amplify the $C A T$ gene.

Production of CBP-tagged SIUBC3 and CAT proteins containing a FLAG epitope was achieved using the pCAL-nFLAG vector (Stratagene). The coding region of SIUBC3 was amplified using primers P10 and P11 and cloned into pCAL-nFLAG to generate pCAL-SIUBC3. The CAT ORF was amplified using primers P7 and P8 and cloned into pCAL-n-FLAG to yield pCAL-CAT. E. coli cells were transformed with pCAL-SIUBC3 and pCAL-CAT, grown to an optical density at $600 \mathrm{~nm}$ of 0.7 , and induced with $0.5 \mathrm{mM}$ isopropyl- $\beta$-D-thiogalactopyranoside. Crude soluble protein was extracted as described (Selth et al. 2005).

Binding experiments were performed as described by Selth and associates (2005) followed by electrophoresis of protein samples and transferring to Immobilon PVDF membrane (Millipore) and blocking with 5\% (wt/vol) nonfat dry milk before incubation with mouse anti-polyHis and anti-FLAG monoclonal antibodies (Sigma-Aldrich, St. Louis). Goat antimouse immunoglobulin $\mathrm{G}$ (IgG)-horseradish peroxidase conjugate was used as the secondary antibody and detected using SuperSignal West Pico chemiluminescent substrate (Quantum Scientific, Clayton South, Australia).

\section{Localization studies using GFP fusion proteins.}

A modified version of shuttle vector pART7 (Gleave 1992), termed pN'gfp (Selth et al. 2005), was used to produce $\beta C 1$ :GFP and SIUBC3:GFP fusion proteins. The SIUBC3 ORF was amplified using the specific primers P13 and P14, digested with $X h o \mathrm{I} / \mathrm{XbaI}$, and ligated into the same sites of pN'gfp to generate an in-frame C-terminal fusion to the GFP gene downstream of the Cauliflower mosaic virus $35 \mathrm{~S}$ promoter. The $\beta C 1$ ORF was cloned into the same sites to obtain $35 \mathrm{~S}-\beta \mathrm{C} 1$ :GFP (Saeed et al. 2007). The pART7-GFP plasmid which expresses untargeted GFP was used as a control. $N$. benthamiana epidermal strips were bombarded and GFP visualized after $48 \mathrm{~h}$ as previously described (Selth et al. 2005).

\section{DNA $\beta$ mutant infectivity assay.}

Site-directed mutagenesis of $\beta C 1$ was undertaken using primers P17 and P15 to amplify a 369-bp DNA $\beta$ fragment (nucleotides 219 to 588) containing a G103A mutation and cloned into pBS- $\beta$ (a full-length clone of CLCuMV DNA $\beta$ in pBluescript II SK+), in which the equivalent wt fragment had been removed, to produce pBS-DNA $\beta$ mut. A pBin-0.2 $\beta$ construct was made by cloning a 280-bp SnaBI/KpnI fragment of pBS-DNA $\beta$ into the binary transformation vector pBin20 (Hennegan and Danna 1998). An infectious head-to-tail 1.2 mer of DNA $\beta$ mutant was constructed by ligating a full-length DNA $\beta$ mutant into the $K p n I$ site of the pBin- $0.2 \beta$ to produce pBin-1.2 $\beta$ mut which contains a single copy of the $\beta C 1$ gene with a G103A mutation. The pBin-1.2 $\beta$ mut construct was introduced into Agrobacterium tumefaciens sp. strain C58 by electroporation. $N$. benthamiana and $N$. tabacum plants were co-agroinoculated with ToLCV and either pBin-1.2 $\beta$ mut or
pBin-1.2 $\beta$ (Saeed et al. 2005), which contains 1.2 mer of wt DNA $\beta$. DNA $\beta$ infection was detected by dot-blot analysis of the newly emerging leaves as described (Stonor et al. 2003) and the expression of $\beta C l$ was tested by Northern blotting assay using total RNA extracted from newly emerging leaves of infected plants following DNase I treatment.

\section{Protein polyubiquitination assay.}

Total protein was extracted from $35 \mathrm{~S}-\beta \mathrm{C} 1$ transgenic tobacco (Saeed et al. 2005) and wt tobacco plants at the six-leaf stage as described (Ozaki et al. 1992). For Western blot assay, the extracted proteins $(50 \mu \mathrm{g})$ were fractionated by $10 \%$ SDSpolyacrylamide gel electrophoresis and transferred by electroblotting onto PVDF membrane (Millipore), which was blocked with $5 \%$ (wt/vol) nonfat dry milk before incubation with mouse antiubiquitin monoclonal antibody (Genescript, U.S.A.). A monoclonal $\beta$-tubulin antibody (Sigma-Aldrich) was used as a control. Goat anti-mouse IgG-horseradish peroxidase conjugate was used as the secondary antibody and detected using SuperSignal West Pico chemiluminescent substrate.

\section{ACKNOWLEDGMENTS}

We thank R. Briddon (National Institute of Biotechnology and Genetic Engineering, Pakistan) for providing the clones of DNA $\beta$, T. Kerppola (University of Michigan) for the vectors pUC19-YC and pUC19-YN, and G. Sarvestani (IMVS, SA) for assistance with the confocal scanning laser microscope. O. Eini was sponsored by the Ministry of Science, Research, and Technology of Iran.

\section{LITERATURE CITED}

Bachmair, A., Becker, F., Masterson, R. V., and Schel, J. 1990. Perturbation of the ubiquitin system causes leaf curling, vascular tissue alterations and necrotic lesions in a higher plant. EMBO (Eur. Mol. Biol. Organ.) J. 9:4543-4549.

Banks, L., Pim, D., and Thomas, M. 2003. Viruses and the 26S proteasome: Hacking into destruction. Trends Biochem. Sci. 28:452-459.

Boisnard-Lorig, C., Colon-Carmona, A., Bauch, M., Hodge, S., Doerner, P., Bancharel, E., Dumas, C., Haseloff, J., and Berger, F. 2001. Dynamic analyses of the expression of the HISTONE::YFP fusion protein in Arabidopsis show that syncytial endosperm is divided in mitotic domains. Plant Cell 13:495-509.

Boutin, J. A. 1997. Myristoylation. Cell Signal 9:15-35.

Briddon, R. W., and Stanley, J. 2006. Subviral agents associated with plant single-stranded DNA viruses. Virology 344:198-210.

Briddon, R. W., Mansoor, S., Bedford, I. D., Pinner, M. S., Saunders, K., Stanley, J., Zafar, Y., Malik, K. A., and Markham, P. G. 2001. Identification of DNA components required for induction of cotton leaf curl disease. Virology 285:234-243.

Briddon, R. W., Bull, S. E., Amin, I., Idris, A. M., Mansoor, S., Bedford, I. D., Dhawan, P., Rishi, N., Siwatch, S. S., Abdel-Salam, A. M., Brown, J. K., Zafar, Y., and Markham, P. G. 2003. Diversity of DNA $\beta$, a satellite molecule associated with some monopartite begomoviruses. Virology 312:106-121.

Brown, J. K. 1992. Whitefly-transmitted geminiviruses and associated disorders in the Americas and the Caribbean basin. Plant Dis. 7:220225.

Chen, Z., and Pickart, C. 1990. A 25-kilodalton ubiquitin carrier protein (E2) catalyzes multi- ubiquitin chain synthesis via lysine 48 of ubiquitin. J. Biol. Chem. 265:21835-21842.

Cui, X., Tao, X., Xie, Y., Fauquet, C. M., and Zhou, X. 2004. A DNA $\beta$ associated with Tomato yellow leaf curl China virus is required for symptom induction. J. Virol. 78:13966-13974.

Cui, X., Li, G., Wang, D., Hu, D., and Zhou, X. 2005. A Begomovirus DNA $\beta$-encoded protein binds DNA, functions as a suppressor of RNA silencing, and targets the cell nucleus. J. Virol. 79:10764-10775.

Deshaies, R. J. 1995. The self-destructive personality of a cell cycle in transition. Curr. Opin. Cell Biol. 7:781-789.

Devoy, A., Soane, T., Welchman, R., and Mayer, R. J. 2005. The ubiquitinproteasome system and cancer. Pages 187-202 in: Essays in biochemistry. R. J. Mayer and R. Layfield, eds. Portland Press, London.

Fondong, V., Reddy, R., Lu, C., Hankoua, B., Felton, C., Czymmek, K., and Achenjang, F. 2007. The consensus N-myristoylation motif of a 
Geminivirus AC4 protein is required for membrane binding and pathogenicity. Mol. Plant-Microbe Interact. 20:380-391.

Gao, G., and Luo, H. 2006. The ubiquitin-proteasome pathway in viral infections. Can. J. Physiol. Pharmacol. 84:5-14.

Garí, E., Piedrafita, L., Aldea, M., and Herrero, E. 1997. A set of vectors with a tetracycline-regulatable promoter system for modulated gene expression in Saccharomyces cerevisiae. Yeast 13:837-848.

Gleave, A. P. 1992. A versatile binary vector system with a T-DNA organisational structure conducive to efficient integration of cloned DNA into the plant genome. Plant Mol. Biol. 20:1203-1207.

Gopal, P., Pravin Kumar, P., Sinilal, B., Jose, J., Kasin Yadunandam, A., and Usha, R. 2007. Differential roles of C4 and $\beta C 1$ in mediating suppression of post-transcriptional gene silencing: Evidence for transactivation by the $\mathrm{C} 2$ of Bhendi yellow vein mosaic virus, a monopartite begomovirus. Virus Res. 123:9-18.

Hennegan, K. P., and Danna, K. J. 1998. Pbin20: An improved binary vector for Agrobacterium-mediated transformation. Plant Mol. Biol. Rep. 16:129-131.

Hu, C.-D., Chinenov, Y., and Kerppola, T. K. 2002. Visualization of interactions among bZIP and Rel family proteins in living cells using bimolecular fluorescence complementation. Mol. Cell 9:789-798.

Jentsch, S. 1992. The ubiquitin-conjugation system. Annu. Rev. Genet 26:179-207.

Jose, J., and Ramakrishnan, U. 2003. Bhendi yellow vein mosaic disease in India is caused by association of a DNA $\beta$ satellite with a begomovirus. Virology 305:310-317

Kon, T., Sharma, P., and Ikegami, M. 2007. Suppressor of RNA silencing encoded by the monopartite tomato leaf curl Java begomovirus. Arch. Virol. 152:1273-1282.

Kraft, E., Stone, S. L., Ma, L., Su, N., Gao, Y., Lau, O., Deng, X. W., and Callis, J. 2005. Genome analysis and functional characterization of the E2 and RING-type E3 ligase ubiquitination enzymes of Arabidopsis. Plant Physiol. 139:1597-1611

Laney, J. D., and Hochstrasser, M. 1999. Substrate targeting in the ubiquitin system. Cell 97:427-430.

Latham, J. R., Saunders, K., Pinner, M. S., and Stanley, J. 1997. Induction of plant cell division by beet curly top gene C4. Plant J. 11:1273-1283.

Moon, J., Parry, G., and Estelle, M. 2004. The ubiquitin-proteasome pathway and plant development. Plant Cell 16:3181-3195.

Moriones, E., and Navas-Castillo, J. 2000. Tomato yellow leaf curl virus, an emerging virus complex causing epidemics worldwide. Virus Res. 71:123-134.

Nagar, S., Pedersen, T. J., Carrick, K. M., Hanley-Bowdoin, L., and Robertson, D. 1995. A geminivirus induces expression of a host DNA synthesis protein in terminally differentiated plant cells. Plant Cell 7:705-719.

Ozaki, M., Fujinami, K., Tanaka, K., Amemiya, Y., Sato, T., Ogura, N., and Nakagawa, H. 1992. Purification and initial characterization of the proteasome from the higher plant Spinacia oleracea. J. Biol. Chem. 267:21678-21684.

Pickart, C. M. 2001. Mechanisms underlying ubiquitination. Annu. Rev. Biochem. 70:503-533.

Piroux, N., Saunders, K., Page, A., and Stanley, J. 2007. Geminivirus pathogenicity protein $\mathrm{C} 4$ interacts with Arabidopsis thaliana shaggy-related protein kinase $\operatorname{AtSK} \xi$, a component of the brassinosteroid signalling pathway. Virology 362:428-440.

Podell, S., and Gribskov, M. 2004. Predicting N-terminal myristoylation sites in plant proteins. BMC Genomics 17:1-15.

Polston, J. E., Bois, D., Serra, C. A., and Concepcion, S. 1994. First report of a tomato yellow leaf curl-like geminivirus in the western hemisphere. Plant Dis. 78:831
Qazi, J., Amin, I., Mansoor, S., Iqbal, M. J., and Briddon, R. W. 2007. Contribution of the satellite encoded gene $\beta \mathrm{C} 1$ to cotton leaf curl disease symptoms. Virus Res. 128:135-139.

Qian, Y., and Zhou, X. 2005. Pathogenicity and stability of a truncated DNA $\beta$ associated with Tomato yellow leaf curl China virus. Virus Res. 109:159-163.

Rojas, M. R., Hagen, C., Lucas, W. J., and Gilbertson, R. L. 2005. Exploiting chinks in the plant's armour: Evolution and emergence of geminiviruses. Annu. Rev. Phytopathol. 43:361-394.

Saeed, M., Behjatnia, S. A. A., Shahid, M., Yusuf, Z., Shahida, H., and Rezaian, M. A. 2005. A single complementary-sense transcript of a geminiviral DNA $\beta$ satellite is determinant of pathogenicity. Mol. PlantMicrobe Interact. 18:7-14.

Saeed, M., Zafar, Y., Randles, J. W., and Rezaian, M. A. 2007. A monopartite begomovirus-associated DNA $\beta$ satellite substitutes for the DNA $\beta$ of a bipartite begomovirus to permit systemic infection. J. Gen. Virol. 88:2881-2889.

Saunders, K., Bedford, I. D., Briddon, R. W., Markham, P. G., Wong, S. M., and Stanley, J. 2000. A unique virus complex causes Ageratum yellow vein disease. Proc. Natl. Acad. Sci. U.S.A. 97:6890-6895.

Saunders, K., Norman, A., Gucciardo, S., and Stanley, J. 2004. The DNA $\beta$ satellite component associated with Ageratum yellow vein disease encodes an essential pathogenicity protein $(\beta \mathrm{C} 1)$. Virology 324:37-47.

Selth, L. A., Dogra, S. C., Rasheed, M. S., Healy, H., Randles, J. W., and Rezaian, M. A. 2005. A NAC domain protein interacts with Tomato leaf curl virus replication accessory protein and enhances viral replication. Plant Cell 17:311-325.

Settlage, S. B., Miller, A. B., Gruissem, W., and Hanley-Bowdoin, L. 2001. Dual interaction of a geminivirus replication accessory factor with a viral replication protein and a plant cell cycle regulator. Virology 279:570-576.

Seufert, W., and Jentsch, S. 1990. Ubiquitin-conjugating enzymes UBC4 and UBC5 mediate selective degradation of short-lived and abnormal proteins. EMBO (Eur. Mol. Biol. Organ.) J. 9:543-550.

Stanley, J., Bisaro, D. M., Briddon, R. W., Brown, J. K., Fauquet, C. M., Harrison, B. D., and Rybicki, E. P. 2005. Geminiviridae. Pages 301-326 in: Virus Taxonomy: Classification and Nomenclature of Viruses: Eighth Report of the International Committee on the Taxonomy of Viruses. C. M. Fauquet, M. A. Mayo, J. Maniloff, U. Desselberger, and L. A. Ball, eds. Elsevier/Academic Press, London.

Stolpe, T., Bublin, C., Marrocco, K., Nick, P., Kretsch, T., and Kircher, S. 2005. In planta analysis of protein-protein interactions related to light signaling by bimolecular fluorescence complementation. Protoplasma 226:137-146.

Stonor, J., Hart, P., Gunther, M., DeBarro, P., and Rezaian, M. A. 2003. Tomato leaf curl geminivirus in Australia: Occurrence, detection, sequence diversity and host range. Plant Pathol. 52:379-388.

Sung, P., Prakash, S., and Prakash, L. 1990. Mutation of cysteine-88 in the Saccharomyces cerevisiae RAD6 protein abolishes its ubiquitin-conjugating activity and its various biological functions. Proc. Natl. Acad. Sci. U.S.A. 87:2695-2699.

Tao, X., and Zhou, X. 2004. A modified viral satellite DNA that suppresses gene expression in plants. Plant J. 38:850-860.

Yang, J.-Y., Iwasaki, Machida, C., Machida, Y., Zhou, X., and Chua, N.-H. 2008. $\beta C 1$, the pathogenicity factor of TYLCCV, interacts with AS1 to alter the leaf development and suppress selective jasmonic acid responses. Genes Dev. 22:2564-2577

Zhou, J., Loh, Y.-T., Bressan, R. A., and Martin, G. B. 1995. The tomato gene Ptil encodes a serine/threonine kinase that is phosphorylated by Pto and is involved in the hypersensitive response. Cell 83:925-935. 